\title{
Detection and assessment of straddling and overriding atrioventricular valves by two dimensional echocardiography
}

\author{
JEFFREY F SMALLHORN*, GIUSEPPI TOMMASINI $\dagger$, FERGUS J MACARTNEY \\ From the Department of Paediatric Cardiology, The Hospital for Sick Children, Great Ormond Street, London
}

SUMMARY Sixteen patients with a straddling tricuspid and two with a straddling mitral valve were identified by two dimensional echocardiography. In all but one the atrioventricular valves appeared at the same level, indicating absence of the ventriculoatrial septum.

A straddling valve was diagnosed by identifying subvalvular apparatus from one atrioventricular valve in both chambers, independent of whether they were ventricles or rudimentary chambers. Further confirmation was obtained during real time study where the valve leaflets appeared to fly through the ventricular septal defect.

Overriding of the valve annulus was greater than $50 \%$ in 12 and less than $50 \%$ in five, with one other patient having none detectable.

The relation of the central fibrous body to the tip of the interventricular septum was reliable in assessing overriding of greater than $50 \%$, but where it was less than $50 \%$ other views were necessary to detect its presence.

The diagnosis of straddling with or without overriding of an atrioventricular valve can be reliably made by two dimensional echocardiography, and carries important implications relating to the type of surgical intervention possible, and in those with a straddling tricuspid valve, the position of the atrioventricular node.

A straddling atrioventricular valve is one whose tensor apparatus arises from both chambers in the ventricular mass. ${ }^{1}$ These two chambers may either be two ventricles, or a main chamber and a rudimentary chamber. In many cases, straddling of the tensor apparatus is associated with overriding of the valve annulus.

Straddling of the valve may have important surgical implications. For example it is impossible to close a ventricular septal defect through which an atrioventricular valve straddles by conventional means without dividing tensor apparatus and making the valve regurgitant.

In the past, diagnosis of such lesions has been impossible clinically, and rather difficult by angiocardiography, because of problems in identifying the tensor apparatus and the relations between the valve annuli and interventricular septum. M-mode echocardiography has provided some clues

* JFS is a British Heart Foundation Junior Research Fellow.

† Present address: Divisione di Cardiochirurgia Infantile, Ospedale Provinciale, Massa, Italy

$\ddagger$ FJM is supported by the British Heart and Vandervell Foundations.

Received for publication 29 January 1981 to the diagnosis of straddling,,$^{2-4}$ but has been unreliable in the diagnosis of overriding and the morphology of the straddling atrioventricular valve. Two dimensional echocardiography permits simultaneous assessment of all echo-producing structures in a given cross section of the heart, thereby allowing a detailed dynamic morphological study of the atrioventricular valves and interventricular septum to be made. ${ }^{5}$ There is little information on its application in the assessment of straddling atrioventricular valves ${ }^{6}$ and for this reason the present study was undertaken. The aims were to see whether two dimensional echocardiography could detect straddling and overriding atrioventricular valves, and delineate the precise relations of the tensor apparatus and annuli to the septum dividing the chambers in the ventricular mass.

\section{Subjects and methods}

Only those cases with two separate atrioventricular valves were included in this study, cases of biventricular and univentricular hearts with common atrioventricular valves being excluded. 
Table 1 Summary of cases studied with univentricular hearts

\begin{tabular}{|c|c|c|c|c|c|c|}
\hline \multirow{2}{*}{$\begin{array}{l}\text { Case } \\
\text { No }\end{array}$} & \multicolumn{2}{|c|}{$\begin{array}{l}\text { Straddling } \\
A V \text { valve }\end{array}$} & \multirow{2}{*}{$\begin{array}{l}\text { Associated } \\
\text { lesions }\end{array}$} & \multirow{2}{*}{$\begin{array}{l}\text { Rudimentary } \\
\text { chamber }\end{array}$} & \multirow{2}{*}{$\begin{array}{l}\text { Arterial } \\
\text { connections }\end{array}$} & \multirow{2}{*}{$\begin{array}{l}\text { Angiocardiographic } \\
\text { confirmation of } \\
\text { annular overriding }\end{array}$} \\
\hline & Right & Left & & & & \\
\hline 1 & Yes & - & $\begin{array}{l}\text { Pulmonary } \\
\text { atresia }\end{array}$ & $\begin{array}{l}\text { Anterior } \\
\text { right }\end{array}$ & $\begin{array}{l}\text { Single outlet } \\
\text { aorta }\end{array}$ & Not detected \\
\hline 2 & Yes & - & Nil & $\begin{array}{l}\text { Anterior } \\
\text { right }\end{array}$ & Discordant & Not detected \\
\hline 3 & Yes & - & Nil & $\begin{array}{l}\text { Anterior } \\
\text { right }\end{array}$ & Discordant & Detected \\
\hline 4 & Yes & - & $\begin{array}{l}\text { Stevosed left } \\
\text { AV valve PS }\end{array}$ & $\begin{array}{l}\text { Anterior } \\
\text { right }\end{array}$ & Discordant & Not detected \\
\hline 5 & Yes & - & Nil & $\begin{array}{l}\text { Anterior } \\
\text { right }\end{array}$ & Discordant & Not detected \\
\hline 6 & Yes & - & $\begin{array}{l}\text { Pulmonary } \\
\text { stenosis }\end{array}$ & $\begin{array}{l}\text { Anterior } \\
\text { right }\end{array}$ & Discordant & Detected \\
\hline 7 & Yes & - & Dextrocardia & $\begin{array}{l}\text { Anterior } \\
\text { right }\end{array}$ & Discordant & Not detected \\
\hline 8 & Yes & - & $\begin{array}{l}\text { Stenosed left } \\
\text { AV valve }\end{array}$ & $\begin{array}{l}\text { Anterior } \\
\text { right }\end{array}$ & Concordant & Not detected \\
\hline 9 & Yes & - & $\begin{array}{l}\text { Pulmonary } \\
\text { stenosis }\end{array}$ & $\begin{array}{l}\text { Anterior } \\
\text { right }\end{array}$ & Concordant & Detected \\
\hline 10 & Yes & - & Nil & $\begin{array}{l}\text { Anterior } \\
\text { right }\end{array}$ & Concordant & Detected \\
\hline 11 & Yes & - & Nil & $\begin{array}{l}\text { Anterior } \\
\text { right }\end{array}$ & Discordant & Not detected \\
\hline 12 & - & Yes & Nil & $\begin{array}{l}\text { Posterior } \\
\text { left }\end{array}$ & Concordant & Not detected \\
\hline
\end{tabular}

AV, atrioventricular; PS, pulmonary stenosis.

The patients were all seen at The Hospital for Sick Children, Great Ormond Street, over a nine month period. In the majority of cases, the presence of straddling and overriding atrioventricular valves was unsuspected before the two dimensional echocardiographic studies were performed. In a few, the angiocardiographic diagnosis had been suggestive, but not certain.

Ventricles, main chambers, and rudimentary chambers are defined as suggested by Tynan and colleagues. ${ }^{7}$ This study includes 16 patients with a straddling right atrioventricular valve, associated with a biventricular heart in five and a univentricular heart in 11. Two further patients had a straddling left atrioventricular valve, one with a univentricular, and the other a biventricular heart: In all but one (case 5 Table 1) straddling was associated with overriding.

The patients were studied using an Advanced Technology Laboratory mechanical sector scanner with 3.0 or $5 \mathrm{MHz}$ transducer. Various standard views were adopted to obtain the required information, as it was obvious from the earlier investigations that combined studies were necessary for an accurate assessment of the atrioventricular valves and subvalvular apparatus. The transducer positions on the chest required to obtain true four chambered and short axis views were variable because of the frequently abnormal relation of the ventricular chambers.

We studied the level of the atrioventricular valves and the type of ventricular septal defect. To determine the degree of overriding the relation between the central fibrous body and interventricular septum was assessed. Straddling was identified by recognising tensor apparatus from one atrioventricular valve in both chambers in the ventricular mass. The direction of movement of atrioventricular valve leaflets was also used to assess the presence and degree of straddling.

\section{Results}

In the four chamber view two atrioventricular valves at the same level were identified in 17 cases, whatever the ventricular morphology. Thus, in these cases no atrioventricular septum was identified (Fig. 1A). In the remaining patient, however, with a straddling right atrioventricular valve an atrioventricular septum was visualised (Fig. 2A,B). Fifteen cases had evidence of overriding involving the right atrioventricular annulus, and two the left. In 12 , overriding was assessed as being greater than $50 \%$ (Fig. 3), these being classified as univentricular hearts with double inlet to the main chamber. In five patients overriding was less than $50 \%$, these being biventricular hearts with one other having no overriding (Fig. 2A). In the 

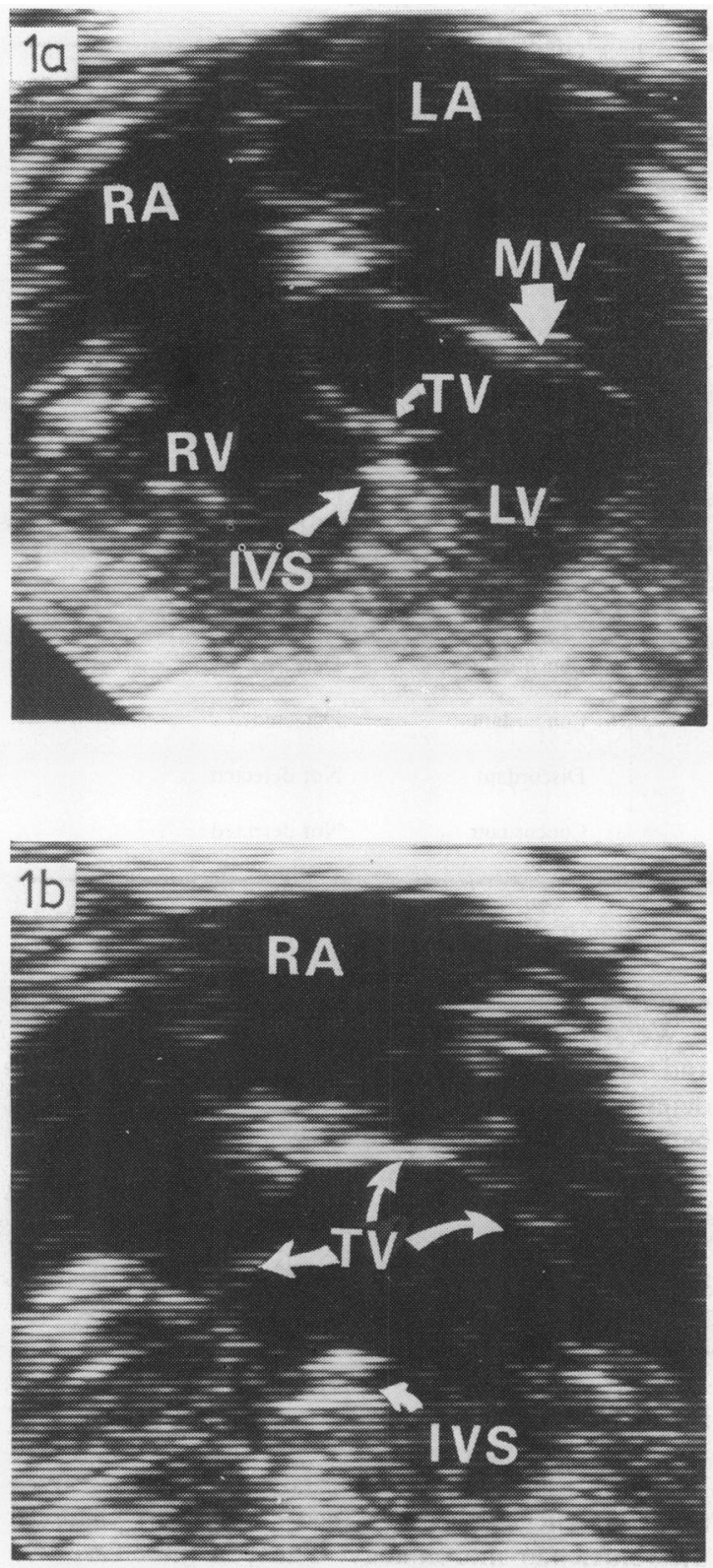

Fig. 1 Upper panel is an apical four chamber view in a patient with a straddling right atrioventricular valve and biventricular heart. In this projection no overriding of the interventricular septum by the tricuspid annulus is seen. Lower panel: the transducer is angled in the same patient to view only the tricuspid valve. The tricuspid annulus is then clearly shown to override the more posterior part of the interventricular septum. $I V S$, interventricular septum; $L A$, left atrium; $L V$, left ventricle; $M V$, mitral valve; $R A$, right atrium; $R V$, right ventricle; TV, tricuspid valve. latter case an intact atrioventricular septum was visualised by two-dimensional echocardiography (Fig. $2 \mathrm{~A}$ ), and at operation the ventricular septal defect was in the trabecular septum extending anteriorly, with its margins being completely bordered by muscle.

In 12 patients with univentricular hearts, the rudimentary chamber was posterior and to the left of the main shamber in one patient and anterior and to the right in 11. In all biventricular hearts the affected atrioventricular valve appeared to move through the ventricular septal defect (Fig. 4) which was best appreciated in real-time studies. Where a rudimentary chamber was present the identification of papillary muscle and chordae helped to confirm the presence of a straddling atrioventricular valve.

A four chamber view in three patients with a straddling right atrioventricular valve gave the appearance of a common anterior leaflet as seen in complete atrioventricular defects (Figs. 5 and 1B). This represented the anterior leaflet of the right atrioventricular valve with tensor apparatus in both chambers.

The morphology of the straddling atrioventicular valve was identified as tricuspid in all cases with a biventricular heart (Fig. 5). In biventricular hearts the tricuspid valve, despite its straddling, still lies mainly over the right ventricle. ${ }^{1}$ Thus ventricular morphology could be deduced from the morphology of the straddling valve.

In eleven patients the arterial connections were discordant and in five concordant, with one having a single outlet aorta and one a double outlet right ventricle (Tables 1 and 2). Two patients had nonstraddling stenosed left sided atrioventricular valves (mitral) and in one case, the straddling right (tricuspid) atrioventricular valve was associated with a criss-cross heart. In one case with a right straddling atrioventricular valve an isolated cleft in the anterior leaflet of the mitral valve was seen, which was confirmed at operation.

Surgical confirmation of a straddling atrioventricular valve was possible in two (Table 2). Necropsy confirmation of straddling was obtained in one case in which the mitral valve was involved. The remaining patients in the study are still alive so further morphological confirmation was not possible. the anglocardiograms of those patients with straddling atrioventricular valves were reviewed and positive confirmation of overriding was possible in $66 \%$ with biventricular and $33 \%$ with univentricular hearts.

\section{Discussion}

There is some confusion about the classification and nomenclature of straddling valves in published reports, so for the sake of simplicity we have adopted 
the terminology suggested by Milo et al. ${ }^{1}$ Straddling valves are defined as valves whose tension apparatus arises on both sides of the septum in the ventricular mass. Overriding is a term indicating that the valve annulus overrides the septum. The atrioventricular valve is assigned to the ventricle which receives the greater share of its annulus. Hence if one atrioventricular annulus is committed entirely to one ventricular chamber while the other overrides, when the degree of overriding is above $50 \%$ the connection is double inlet, whereas when it is below $50 \%$ the connection is concordant, discordant, or ambiguous, depending on the morphology of the atria and ventricles. Furthermore, because the annulus cannot be separated from the sleeve of inlet ventricular musculature to which it is connected, and the inlet musculature is the hallmark of a ventricle, hearts with a double inlet connection are considered univentricular, whereas concordant, discordant, and ambiguous connections are characteristic of biventricular hearts. Note that this nomenclature fulfils the philosophy that structures should be defined in terms of their constituent parts since a ventricle is defined in terms of its inlet (and
Fig. 2 (a) Subxiphoid four chamber view in a patient with biventricular heart and straddling tricuspid septal leaflet, confirmed at operation. A ventriculoatrial septum is seen, indicated by the arrows, but no ventricular septal defect. (b) Recorded in a subxiphoid long axis projection showing the straddling septal tricuspid leaflet. LAV, left atrioventricular valve; LVOT, left ventricular outflow tract; $R A V$, right atrioventricular valve; VS, intraventricular septum (for remaining abbreviations see Fig. 1).

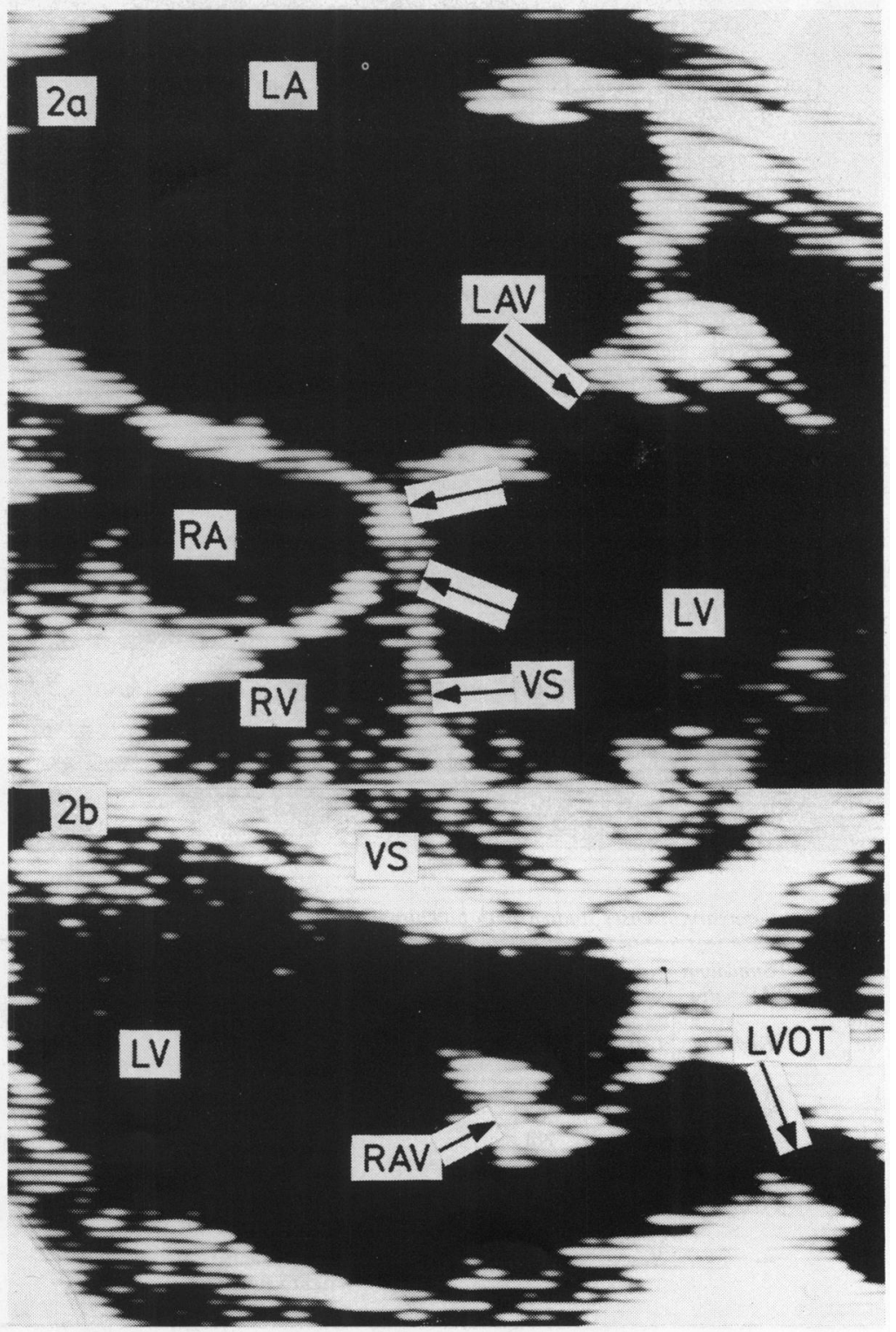




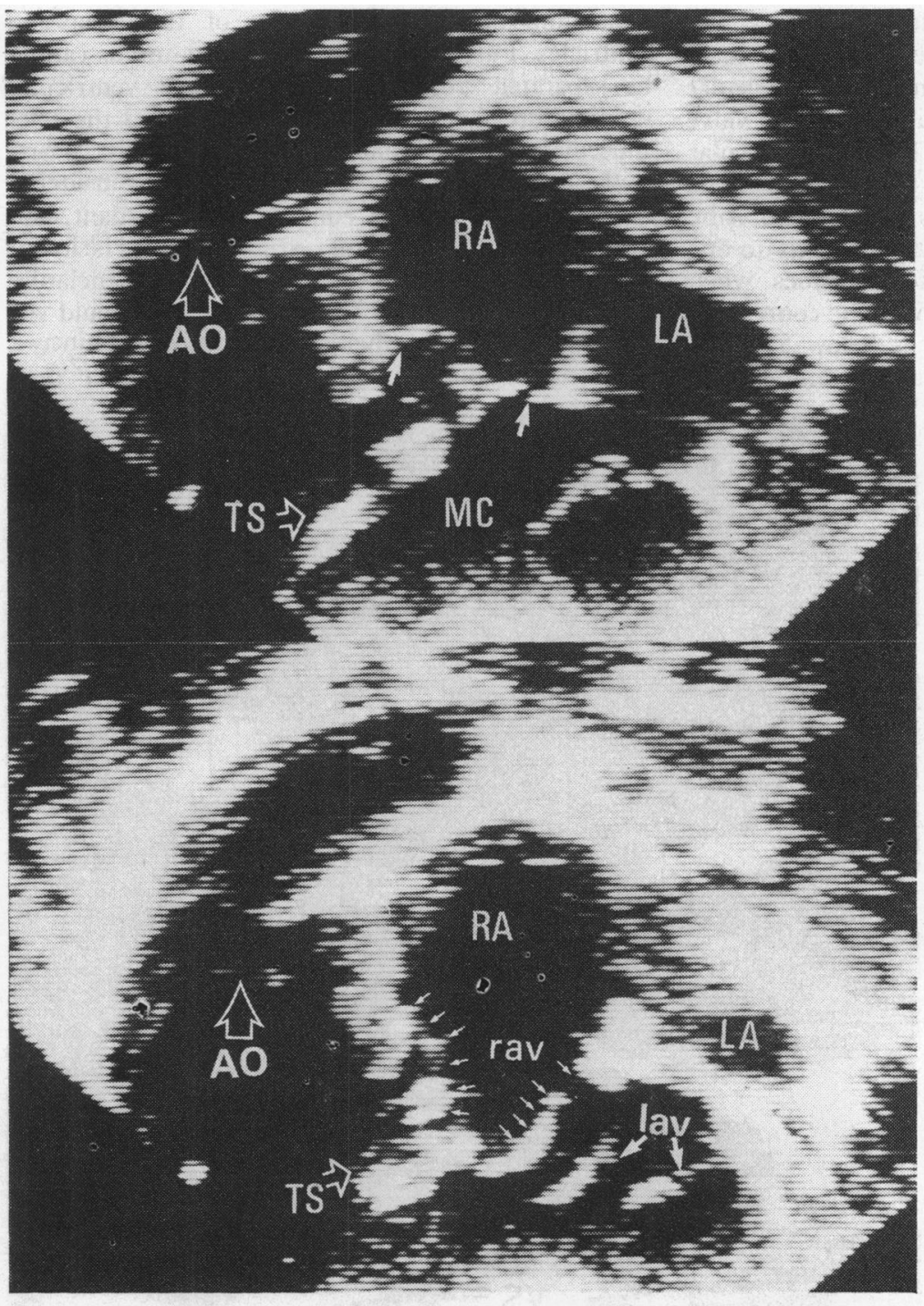

Fig. 3 Subxiphoid four chamber cut in a patient with a double inlet univentricular heart and two atrioventricular valves. The upper panel taken during systole shows the right atrioventricular valve annulus (indicated by the solid arrows) overriding the trabecular septum. The lower panel during diastole shows the right sided atrioventricular valve (indicated by the small arrows), having leaflets and tensor apparatus in both chambers. The lateral leaflet straddles the bulboventricular foramen. lav, left atrioventricular valve; $M C$, main chamber; rav, right atrioventricular valve; $T S$, trabecular septum (for remaining abbreviations see Fig. 1 and 2).

Table 2 Summary of cases studied with biventricular hearts

\begin{tabular}{|c|c|c|c|c|c|c|}
\hline \multirow{2}{*}{$\begin{array}{l}\text { Case } \\
\text { No }\end{array}$} & \multicolumn{2}{|c|}{$\begin{array}{l}\text { Straddling } \\
A V \text { valve }\end{array}$} & \multirow{2}{*}{$\begin{array}{l}\text { Associated } \\
\text { lesions }\end{array}$} & \multirow{2}{*}{$\begin{array}{l}\text { Arterial } \\
\text { connections }\end{array}$} & \multirow{2}{*}{$\begin{array}{l}\text { Surgical } \\
\text { confirmation }\end{array}$} & \multirow{2}{*}{$\begin{array}{l}\text { Angiocardiographic } \\
\text { confirmation of } \\
\text { annular overriding }\end{array}$} \\
\hline & Right & Left & & & & \\
\hline 1 & Yes & - & Nil & Discordant & - & Detected \\
\hline 2 & Yes & - & Nil & Discordant & - & Not detected \\
\hline 3 & Yes & - & Nil & Discordant & - & Detected \\
\hline 4 & Yes & - & Criss-cross heart & Discordant & - & Detected \\
\hline 5 & Yes & - & $\begin{array}{l}\text { Cleft in anterior } \\
\text { leaflet of mitral } \\
\text { valve }\end{array}$ & Concordant & Yes & Not detected \\
\hline 6 & - & Yes & $\mathrm{Nil}$ & $\begin{array}{l}\text { Double outlet } \\
\text { right ventricle; } \\
\text { anterior aorta }\end{array}$ & Yes & Detected \\
\hline
\end{tabular}


trabecular) musculature.

While we endorse the concept of Milo et al. ${ }^{1}$ that common atriventricular valves usually straddle, we have elected to discuss all common valves together in a separate communication. ${ }^{8}$

At present, demonstration of a straddling valve in association with a univentricular heart is of small practical importance, since it is unlikely to affect surgical management. On the other hand, in biventricular hearts, foreknowledge of the presence of straddling is of great importance to the surgeon when planning surgical repair. Simple closure of a ventricular septal defect can be made very difficult if straddling occurs, as damage to subvalvular apparatus can render the atrioventricular valve regurgitant, hence necessitating replacement with another valve. ${ }^{9} 10$ Furthermore, the presence of straddling also affects the disposition of the cardiac conducting tissue, most importantly in hearts with atrioventricular concordance. In contrast to all other hearts with this atrioventricular connection, the atrioventricular node may be situated posterior to its anticipated site in the triangle of Koch. ${ }^{1}$ The conduction tissue continues from this abnormal
Fig. 4 Apical four chamber view in a patient with a straddling tricuspid valve and a biventricular heart. The tip of the tricuspid septal leaflet passes through the ventricular septal defect. $C F B$, central fibrous body (for remaining abbreviations see Fig. 1 and 2).
Fig. 5 Apical view in a patient with a biventricular heart and straddling right atrioventricular valve. The transducer is rotated to visualise mainly the tricuspid valve and annulus. The anterior leaflet has a similar appearance to that seen in a complete atrioventricular canal defect (see Fig. 1 and 2 for abbreviations).
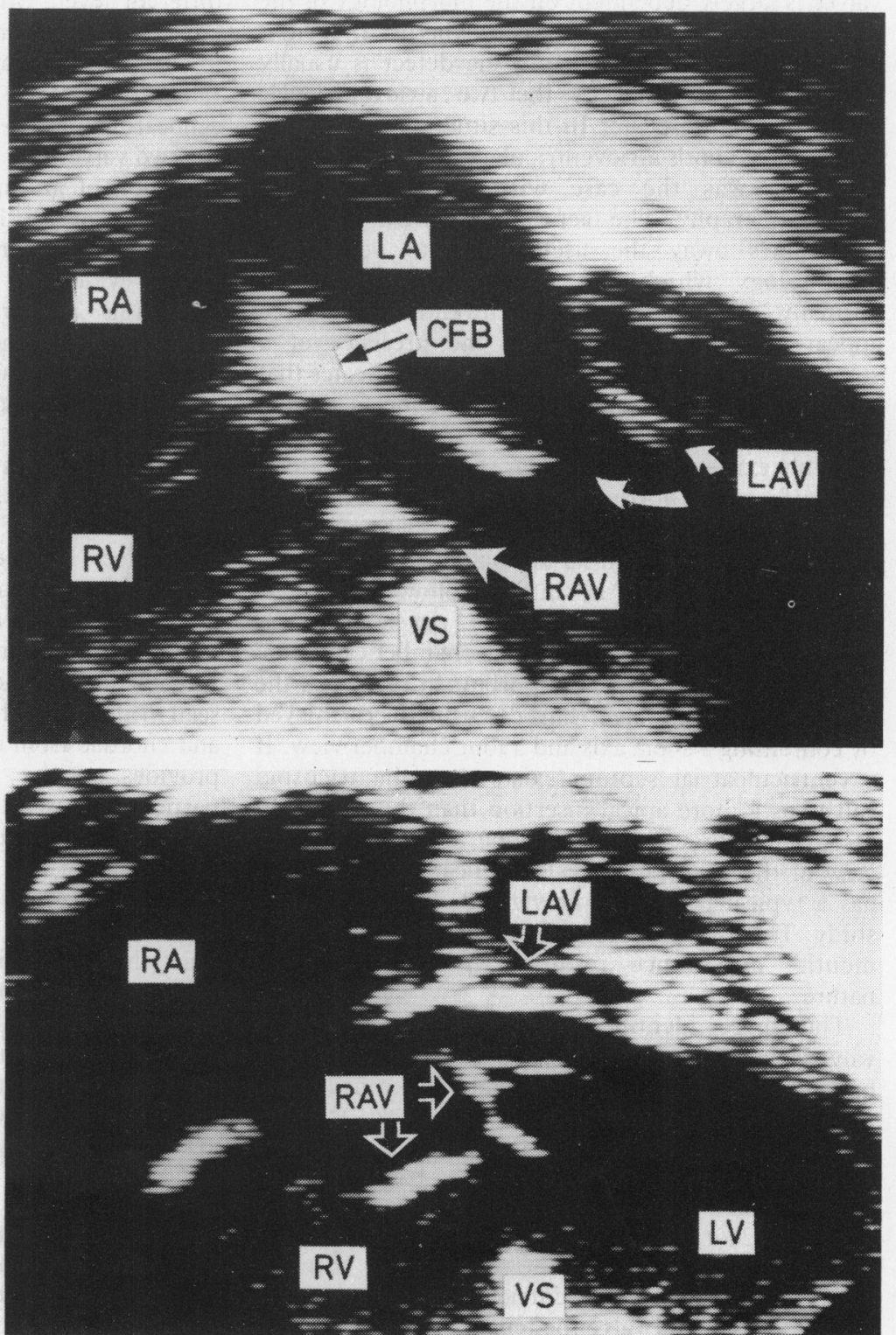
posterolateral node onto the posterior rim of the ventricular septal defect. It is worth noting that of four hospital survivors of operation for right-sided straddling tricuspid valve, three had complete heart block after operation. ${ }^{10}$

In the past neither angiocardiography nor $\mathrm{M}$-mode echocardiography could provide these answers with sufficient reliability, though with the former technique clues could be obtained from recognition of annular overriding and streaming of contrast medium from atrial injections. ${ }^{6} 11$ The relation of the ventricular septal defect and the two atrioventricular valves is largely dependent on the morphology of the one which straddles, regardless of whether it is right or left sided. If it is tricuspid the defect is usually posterior, and roofed by the two atrioventricular valves in continuity. ${ }^{1} 12$ In this situation one should expect to see both atrioventricular valves at the same level, as was the case with two dimensional echocardiography. The fact that they are at the same level takes away the useful clue to ventricular morphology which the ventriculoatrial septum normally affords. ${ }^{13}$ If the atrioventricular valves appear at a different level in the presence of a straddling tricuspid valve (Fig. $2 \mathrm{~A}$ ) this indicates that a ventriculoatrial septum exists, and hence a normal posterior interventricular septum. The defect then probably exists in the trabecular septum with its total circumference bordered by muscle. This has important surgical implications as the atrioventricular node will be situated in its normal site.

The morphology of a ventricle follows that of its connecting atrioventricular valve. In some cases where the trabecular pattern of the chamber cannot be positively identified, it is important to recognise the morphology of the valve. This can usually be achieved by combining a short axis and a four chamber view. If a ventriculoatrial septum exists then the tricuspid valve has a more apical insertion than the mitral. In cases where they are at the same level, a short axis view of the tricuspid reveals a trileaflet valve which has a typical pattern of movement during real-time study. The mitral valve on the other hand, has a "fish mouth" appearance resulting from its bicuspid nature.

The correct identification of each atrioventricular valve is not always easy in the short axis view, and we have additionally used a cut in which the transducer is rotated to visualise only the tricuspid valve, annulus, and right ventricle. This two chamber view readily delineates the trileaflet pattern of the tricuspid valve (Fig. 1B and 5). If further confirmation is needed the pattern of chordal insertions has also been useful. In a tricuspid valve those from the septal leaflet normally insert into the right ventricular septal surface, whereas in a mitral valve the tensor apparatus is more apically placed. These specific features have arisen from a current study on the reliability of twodimensional echocardiography in assessing atrioventricular valve morphology. By combining these various projections, we have rarely failed correctly to identify the morphology of the atrioventricular valves when adequate images are obtained.

In the rarer case of straddling mitral valve, the defect is normally anterior, ${ }^{1}$ so unless the defect excavates posteriorly to a considerable degree, one might expect to find the atrioventricular valves at a different level. One case of straddling mitral valve, however, was recorded with a posterior defect, ${ }^{12}$ and in our one case confirmed at necropsy, the mitral and tricuspid valves were at the same level on echocardiography. At necropsy, continuity between the two valves was seen to exist through the posterior extension of an anterior defect. Thus, a straddling atrioventricular valve should be suspected whenever both valves are seen on the same horizontal plane, but further evidence is required to make a firm diagnosis, since this appearance may also occur in atrioventricular and other inlet defects, and univentricular hearts without straddling.

Normally during diastole, the atrioventricular valve leaflets oppose the interventricular septum when the subvalvular apparatus is contained in the appropriate ventricle. At most, the central portion of the leaflet may bow towards the opposite ventricle through an inlet defect. If some of the tensor apparatus is inserted in the opposite chamber then the particular leaflet involved moves in that direction, and the free edge of the leaflet flies through the septal defect. This is a valuable sign, as actual tensor apparatus may not be seen in all cases. The identification of papillary muscle and chordae from one valve in the opposite chamber provides positive confirmation of straddling. It is particularly useful in univentricular hearts with a rudimentary chamber and two atrioventricular valves, where both at first glance appear to be committed to the main chamber. If a dense echo representing a papillary muscle is seen in this chamber this indicates that the valve is partially committed to the rudimentary chamber.

In a short axis view straddling of one atrioventricular valve can also be identified when chordae from that valve are seen in the opposite chamber. This is best appreciated in a scan from short axis to four chamber. This view of the straddling atrioventricular valve also provides valuable information about the relation of the leaflets to the interventricular septum. Even though the two atrioventricular valves lie at the same level, their orientation is frequently abnormal, so that their junction may not be seen at all in standard 
projections. The distortion of the anatomy is such that in some cases one atrioventricular valve is seen in a short axis projection and demonstrates the straddling, while the other valve is seen in a long axis projection. This stresses the importance of varying the views to obtain the information in complex lesions.

A characteristic anatomical feature of straddling and/or overriding atrioventricular valves is that the atrial and ventricular septa are malaligned. ${ }^{1} 12$ The problem with assessing the alignment of the interventricular septum and interatrial septum by two dimensional echocardiography is that normally, by varying the transducer angulation, some malalignment can be produced. Also in atrioventricular discordance the interventricular septum and interatrial septum are malaligned even in the absence of straddling. ${ }^{14}$ Because of this we have used the relation of the interventricular septum to the central fibrous body to assess the presence or absence of overriding. Where overriding is greater than $50 \%$ the four chambered view reliably detects its presence, but when it is less than $50 \%$ other views are necessary. We have found most helpful the view in which the tricuspid annulus and interventricular septum are visualised without the mitral annulus (Fig. 1B). We suggest that the standard apical four chamber projection fails to detect minor degrees of overriding because the ventricular septum is cut too far anteriorly.
In cases with a straddling tricuspid valve there is a displacement of the normal interventricular septum such that, posteriorly, it does not run to the crux of the heart. Elsewhere, its orientation may be normal. Hence, in a cut where both atrioventricular valves are seen, the displaced portion of the interventricular septum may not be visualised. The presence of overriding may not be detected until the transducer is rotated so as to cut the septum more posteriorly (Fig. 6).

In early anatomical reports of straddling right atrioventricular valves the resemblance between the appearance of the straddling tricuspid valve and a common atrioventricular valve was emphasised. ${ }^{15}$ While these are in fact very different entities they frequently have in common the presence of a bridging anterior leaflet. In three of our cases the tricuspid valve had the appearance of a common anterior leaflet seen in atrioventricular defects (Figs. 1B and 5) with chordae from that leaflet being seen in both chambers. In all of these patients a second atrioventricular valve was identifiable, thus differentiating them from a case with atrioventricular defect. This view, mimicking a common atrioventricular valve, is obtained by rotating the transducer from a straight four chamber projection, where both atrioventricular valves are seen to one where only the tricuspid valve and interventricular septum are seen. When seen, this
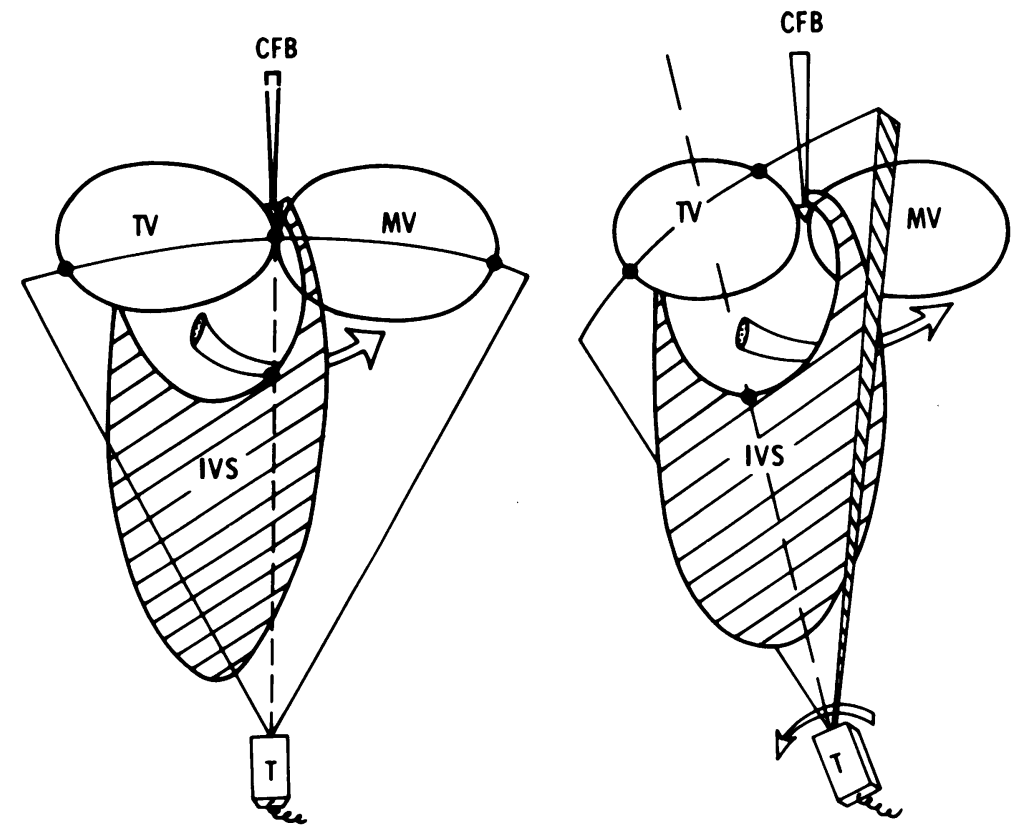

Fig. 6 Schematic diagram of the ultrasonic projections necessary to determine the degree of tricuspid annular overriding. The illustration on the left shows no overriding when a straight four chamber view is obtained, the central fibrous body being in line with the tip of interventricular septum. The diagram on the right is obtained with the transducer angled to visualise only the relation to the tricuspid annulus to the more posterior part of the interventricular septum. Note here that the tricuspid annulus now overrides the more posterior part of the interventricular septum. VSD, ventricular septal defect (for remaining abbreviations see Fig. 1 and 4). 
sign presumably indicates that both the septal and anterior tricuspid leaflets straddle the interventricular septum.

One measure of the confidence placed in noninvasive methods of diagnosis is the extent to which they alter decisions about patient management. In a number of these cases, proposed corrective surgery was abandoned in favour of simpler palliation because of echocardiographic demonstration of straddling. The abnormalities shown were so obvious and so in keeping with pathological descriptions, that no other course seemed reasonable. Ironically, it was precisely this confidence in the preoperative diagnosis which prevented our obtaining anatomical confirmation at open heart surgery. Clearly, the detailed reliability of the diagnosis will only become apparent when the echocardiographic, operative, and necropsy appearances can be compared in a large series of patients with this unusual anomaly.

\section{References}

1 Milo S, Ho SY, Macartney FJ, et al. Straddling and overriding atrioventricular valves: morphology and classification. Am 7 Cardiol 1979; 44: 1122-34.

2 LaCorte MA, Fellows KE, Williams RG. Overriding tricuspid valve: echocardiographic and angiocardiographic features. Am $\mathcal{F}$ Cardiol 1976; 37: 911-9.

3 Seward JB, Tajik AJ, Ritter DG. Echocardiographic features of straddling tricuspid valve. Mayo Clin Proc 1975; 50: 427-34.

4 Mortera C, Hunter S, Terry G, Tynan M. Echocardiography of primitive ventricle. $\mathrm{Br}$ Heart $\mathcal{J}$ 1977; 39: 847-55.

5 Tajik AJ, Seward JB, Hagler DJ, Mair DD, Lie JT. Two-dimensional real-time ultrasonic imaging of the heart and great vessels. Technique, image orientation, structure identification, and validation. Mayo Clin Proc 1978; 53: 271-303.
6 Aziz KU, Paul MH, Muster AJ, Idriss FS. Positional abnormalities of atrioventricular valves in transposition of the great arteries including double outlet right ventricle, atrioventricular valve straddling and malattachment. Am f Cardiol 1979; 44: 1135-45.

7 Tynan M, Becker AE, Macartney FJ, Quero-Jiménez M, Shinebourne EA, Anderson RH. Nomenclature and classification of congenital heart disease. Br Heart $\mathcal{F}$ 1979; 41: 544-53.

8 Smallhorn JF, Tommasini G, Macartney FJ. Twodimensional echocardiographic assessment of atrioventricular valves in univentricular hearts. Br Heart $\mathcal{F} 1981$; 46: $30-4$.

9 Tabry IF, McGoon DC, Danielson GK, Wallace RB, Tajik AJ, Seward JB. Surgical management of straddling atrioventricular valve. $\mathcal{F}$ Thorac Cardiovasc Surg 1979; 77: 191-201.

10 Pacifico AD, Soto B, Bargeron LM Jr. Surgical treatment of straddling tricuspid valves. Circulation 1979; 60: 655-64.

11 Liberthson RR, Paul MH, Muster AJ, Arcilla RA, Eckner FAO, Lev $M$. Straddling and displaced atrioventricular orifices and valves with primitive ventricles. Circulation 1971; 43: 213-26.

12 Bharati S, McAllister HA Jr, Lev M. Straddling and displaced atrioventricular orifices and valves. Circulation 1979; 60: 673-84.

13 Foale RA, Somerville J. Ventricular morphologytwo-dimensional echocardiographic recognition in complex congenital heart disease (abstract). Br Heart $\mathcal{F}$ 1980; 43: 105-6.

14 Anderson RH, Becker AE, Arnold R, Wilkinson JL. The conducting tissues in congenitally corrected transposition. Circulation 1974; 50: 911-23.

15 Rastelli GC, Ongley PA, Titus JL. Ventricular septal defect of atrioventricular canal type with straddling right atrioventricular valve and mitral valve deformity. Circulation 1968; 37: 816-25.

Requests for reprints to Professor F J Macartney, The Hospital for Sick Children, Great Ormond Street, London WCIN 3JH. 